\title{
IRON BASED SOFT MAGNETIC COMPACTED MATERIALS
}

\author{
Ján FÜZER*, Jana FÜZEROVÁ ${ }^{* *}$, Peter KOLLÁR*, Mária FÁBEROVÁ ${ }^{* * *}$, Radovan BUREŠ ${ }^{* * *}$ \\ *Institute of Physics, Faculty of Science, Pavol Jozef Šafárik University, Park Angelinum 9, 04023 Košice, Slovak Republic \\ tel. +421 55234 2586, e-mail: jan.fuzer@upjs.sk \\ ${ }^{* *}$ Faculty of Mechanical Engineering, Technical University of Košice, Letná 1, 04200 Košice, Slovak Republic \\ *** Institute of Materials Research, Slovak Academy of Sciences, Watsonova 47, 04001 Košice, Slovak Republic
}

\begin{abstract}
Soft magnetic materials play an important role in broad applications, such as transformers and electrical motors. There is an interest in bulk soft magnetic materials because of the demand for miniaturization of cores. We have prepared bulk samples in the form of the small cylinders with good soft magnetic properties. The frequency dependence of magnetic properties is studied, and it is attributed mainly to the structure of the initial powder and domain wall damping. The good combination of various shapes and good soft magnetic properties indicates the possibility of future development as a new soft magnetic compacted material.
\end{abstract}

Keywords: soft magnetic material, magnetic cores, eddy current losses, nanocrystalline materials

\section{INTRODUCTION}

Soft magnetic alloys are used in many areas including transformers for electrical energy distribution, power electronics for small and large-scale power management, pulse power devices, telecommunication devices, and sensors. The large values for the maximum induction and relative magnetic permeability, low coercive fields and low core losses are the essential requirements for soft magnetic alloys used in applications. There is a limitation of laminated steels and magnetic ribbons in applications consisting of their shape limitation. The main advantage of the compacted materials is the shape flexibility. The amorphous Vitroperm $\left(\mathrm{Fe}_{73} \mathrm{Cu}_{1} \mathrm{Nb}_{3} \mathrm{Si}_{16} \mathrm{~B}_{7}\right)$ material is produced by rapid solidification as an originally amorphous ribbon, which is subsequently annealed above its crystallization temperature [1]. One of the ways to prepare bulk material is compaction of powder produced by milling of amorphous or nanocrystalline ribbons [2]. Soft magnetic composites (SMCs) are typically produced by powder processing methods, allowing a net-shape production for a wide variety of shapes and sizes [3]. Magnetic powder parts are produced from powder particles each covered by insulating coatings, which cause a barrier to particle-to-particle eddy current paths under ac magnetization hence minimizing eddy current losses. The amount of insulating materials should be minimized to maintain the permeability and saturation magnetization at a high level. Low resistivity material is used for dc applications but alloys with high resistivity are needed to minimize eddy current loss for high-frequency operation.

\section{EXPERIMENTAL}

We have prepared two series of the bulk samples. The initial material of the first series is - amorphous ribbon $\mathrm{Fe}_{73} \mathrm{Cu}_{1} \mathrm{Nb}_{3} \mathrm{Si}_{16} \mathrm{~B}_{7}$, supplied by Vacuumschmelze, Germany via melt spinning technique. The ribbon was milled (R) or cryomilled (L) using a RETSCH PM4000 planetary ball mill. The samples were consolidated at 700 $\mathrm{MPa}$ for $5 \mathrm{~min}$ at $500^{\circ} \mathrm{C}$. The second series - consisting of Iron powders Somalloy (S), provided by Höganäs $A B$, Sweden and flakes $\mathrm{Fe}_{73} \mathrm{Cu}_{1} \mathrm{Nb}_{3} \mathrm{Si}_{16} \mathrm{~B}_{7}$ (VPM), supplied by
Vacuumschmelze, Germany. The samples were consolidated at $800 \mathrm{MPa}$ for $5 \mathrm{~min}$. at room temperature. The compacts were cured for $60 \mathrm{~min}$. in an electric furnace in Argon atmosphere at a temperature of $520^{\circ} \mathrm{C}$ $(\mathrm{L}, \mathrm{R})$ or at a $530^{\circ} \mathrm{C}(\mathrm{S}-\mathrm{VPM})$, respectively. The electrical resistivity was measured by the Van der Pauw method. The DC hysteresis loops at maximum flux density of $0.1 \mathrm{~T}$ and $0.2 \mathrm{~T}$ were measured by a fluxmeter based hysteresisgraph. The AC hysteresis loops were measured by AC hysteresis graph MATS-2010SA. Complex permeability spectra were measured with an impedance analyser HP 4194A.

\section{RESULTS}

The inductance and the resistance of the samples were measured to characterize the magnetic permeabilities. In this case, each toroidal sample was modelled as an ideal inductor, in series with an ideal resistor. The real part $\left(\mu^{\prime}\right)$ and imaginary $\left(\mu^{\prime \prime}\right)$ part of the initial complex permeability were determined from the inductance $L_{s}$ and resistance $R_{s}$ of the coil on the toroidal sample using the following relations:

$$
\begin{aligned}
& \mu^{\prime}=\frac{L_{s}}{L_{0}}=\frac{L_{s} 2 \pi}{\mu_{0} N^{2} h \ln \left(\frac{r_{2}}{r_{1}}\right)}, \\
& \mu \mu^{\prime \prime}=\frac{R_{s}-R_{0}}{\omega L_{0}}=\frac{\left(R_{s}-R_{0}\right) 2 \pi}{\omega \mu_{0} N^{2} h \ln \left(r_{2} / r_{1}\right)},
\end{aligned}
$$

where $L_{s}$ is the self-inductance of sample core, $L_{0}$ is derived from geometrical relations showing the inductance of the winding of the coil without the sample core, $R_{0}$ is the resistance of the coil without the sample core, $N$ is the number of turns of the coil, $h$ is the height, $r_{1}, r_{2}$ is the inner and outer radius of the toroidal sample, respectively, $\omega$ is the angular frequency.

The magnetic properties of the soft magnetic bulk alloys $\mathrm{Fe}_{73} \mathrm{Cu}_{1} \mathrm{Nb}_{3} \mathrm{Si}_{16} \mathrm{~B}_{7}$ prepared from powder alloy by compaction are influenced by the morphology of the initial powder. This influences the density, the electrical 
resistivity and electromagnetic properties of the resulting bulk alloys.

In the first series of samples the milling was at room temperature - sample R. In the second series we investigated the milling at temperature of liquid nitrogen sample L: sample $\mathrm{R}$ - amorphous ribbon milled for 6 hours, consolidated at $500^{\circ} \mathrm{C}$ for $5 \mathrm{~min}$, annealed at $540^{\circ} \mathrm{C}$ for 60 min., sample L - amorphous ribbon cryomilled for 6 hours, consolidated at $500^{\circ} \mathrm{C}$ for $5 \mathrm{~min}$, annealed at $540^{\circ} \mathrm{C}$ for $60 \mathrm{~min}$.

From the previous experiments [4] the X-ray diffraction patterns of short-time (6h) ball-milling of $\mathrm{Fe}_{73} \mathrm{Cu}_{1} \mathrm{Nb}_{3} \mathrm{Si}_{16} \mathrm{~B}_{7}$ ribbons indicate that no influence on its structure during the milling and the powder remained amorphous. Particle size of more than $95 \%$ of particles after milling at room temperature is from $50 \mu \mathrm{m}$ to 300 $\mu \mathrm{m}$, but cryomilled powders have smaller particle sizes, from $20 \mu \mathrm{m}$ to $150 \mu \mathrm{m}$, Fig 1, Fig 2. The resulting particle size distribution may affect the density of the compacted material. The compacted disk L has higher value of the density than disk R, Tab. 1.

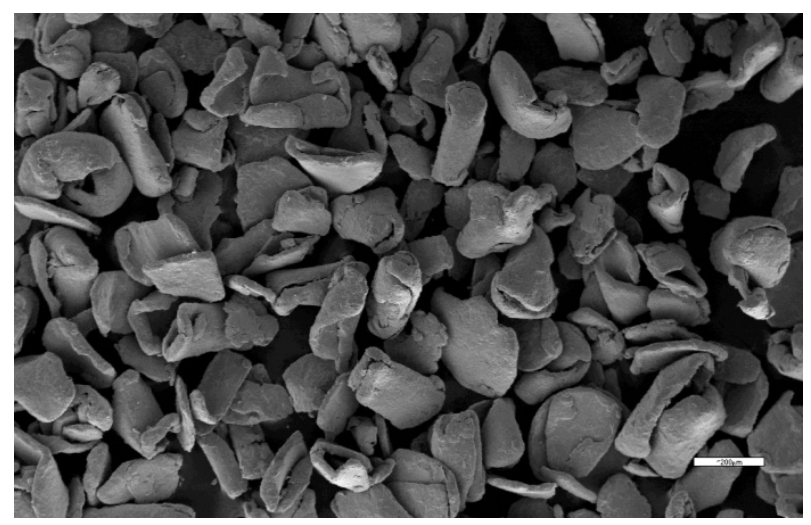

Fig. 1 Fracture of the milled Vitroperm sample R observed by SEM

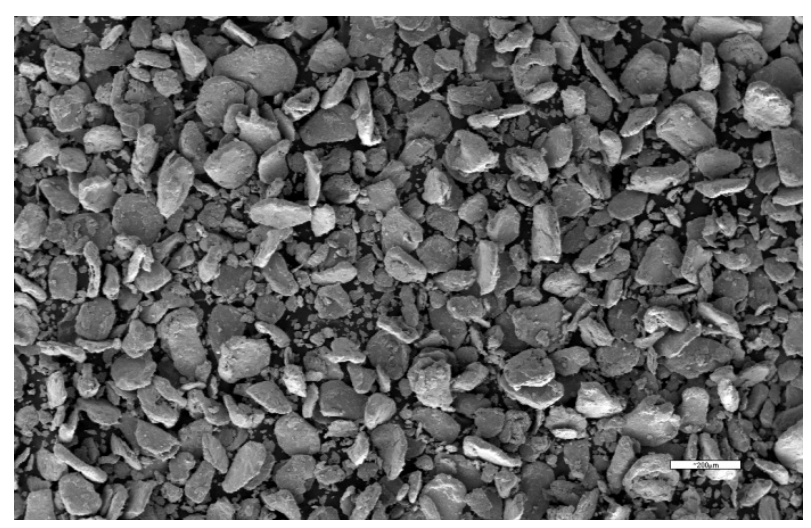

Fig. 2 Fracture of the milled Vitroperm sample L observed by SEM

At high content of small particles high real $\mu^{\prime}$ part of the permeability cannot be expected. On the other hand, reducing the eddy current loss of bulk alloy from cryomilled powder also hinders the core loss at higher frequency [4]. Fig. 3 shows the frequency spectra of real $\mu^{\prime}$ and imaginary $\mu^{\prime \prime}$ part of the complex permeability in powder cores prepared from different powders. It can be seen that real $\mu^{\prime}$ part of the sample L keep almost stable at low frequency region with slight drop in permeability. On the other hand, the real part of the sample $\mathrm{R}$ starts from 6 times higher value of permeability (at $100 \mathrm{~Hz}$ ) but there is the steep drop in the permeability and after that the value of permeability is decreasing slowly and smoothly.

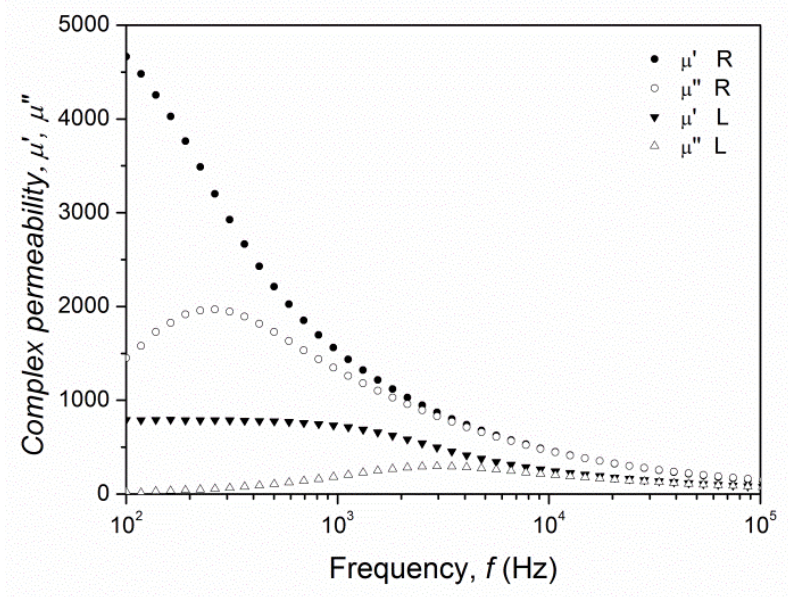

Fig. 3 Comparison of the real $\mu^{\prime}$ and imaginary $\mu^{\prime \prime}$ part of the complex permeability $\mu$ of $\mathrm{L}$ and $\mathrm{R}$ samples, respectively

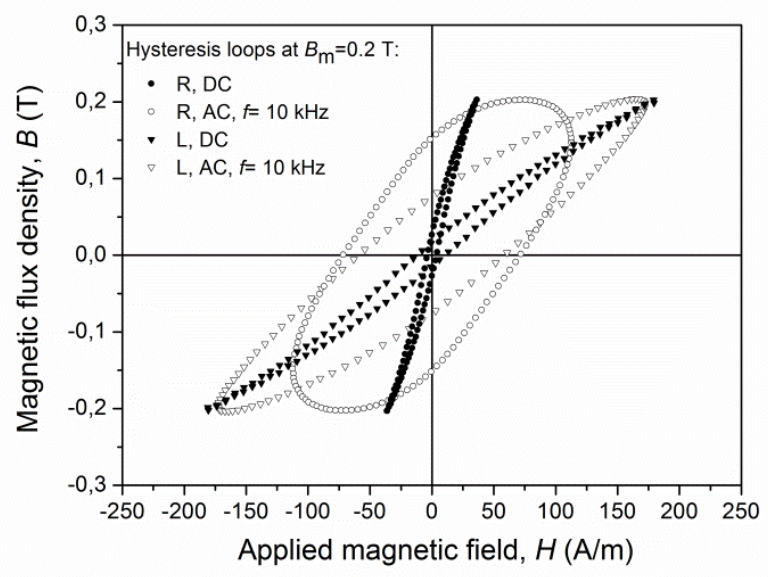

Fig. 4 DC and AC hysteresis loops of bulk R and L cores

The DC and AC hysteresis loops are given in Fig. 4. The peak permeability as well the shapes of the hysteresis loops, the rectangularity are different with the initial powder material. The hysteresis of a soft ferromagnetic material depends on the irreversible magnetization process and is principally determined by pinning of domain wall motion. The hysteresis losses are partly due to pinning sites from imperfections in the material and stresses introduced in the material at a compaction.

In the case of the bulk metallic Fe-based samples consisting of Iron powders (S) and flakes of $\mathrm{Fe}_{73} \mathrm{Cu}_{1} \mathrm{Nb}_{3} \mathrm{Si}_{16} \mathrm{~B}_{7}$ (VPM) with the different content (0, 5, $30,50 \mathrm{wt} \%$ of VPM), the volume of pores increases with increasing VPM content and it affects magnetic properties directly. Somaloy powder has average particle diameter of $120 \mu \mathrm{m}$, shown in Fig. 5. Vitroperm particles are flat and mostly uniform thickness, shown in Fig. 6. Mean size of particles is $200-225 \mu \mathrm{m}$ with normal gauss distribution. Shape descriptors indicated irregular shape of the particles. Density measurements exhibited dependence on 
the VPM content and with an increase in VPM content resulting in a decrease in density. Porosity acts as areas of demagnetization, reducing the saturation magnetization but increasing the specific resistivity of the samples.

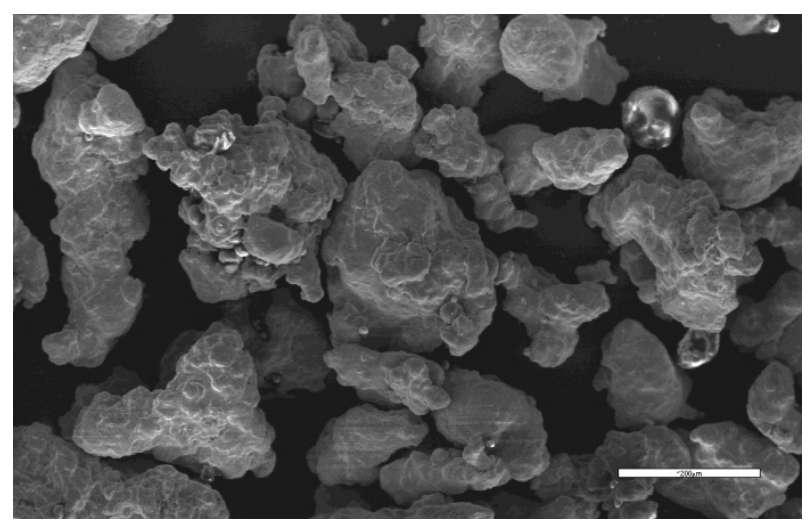

Fig. 5 Fracture of the sample Somaloy ${ }^{\circledR 700}$ powder observed by SEM

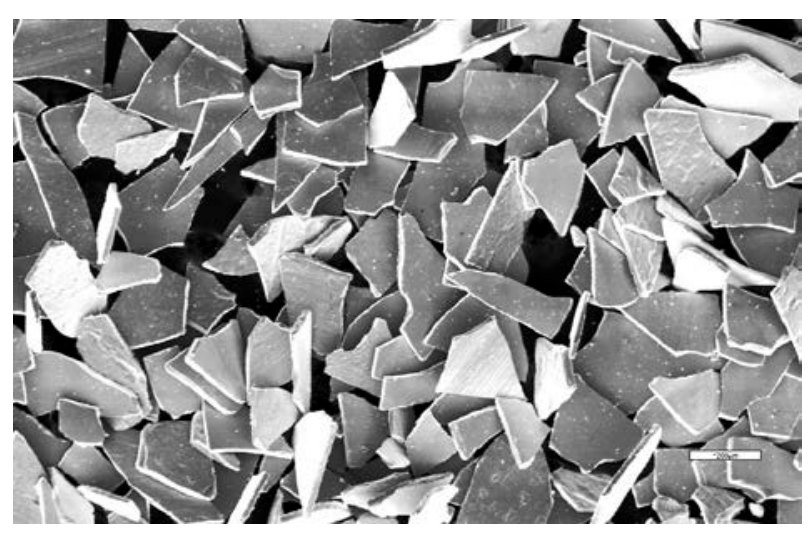

Fig. 6 Fracture of the sample Somaloy ${ }^{\circledR 7} 700$ powder observed by SEM

Although pores and grain boundaries obstruct the movement of domain wall. The complex permeability of the prepared samples shows dependence on their initial powder morphology and the content of two ferromagnetic phases, Fig. 7. The increase in the resistivity leads to an enhancement the real part of permeability at higher frequencies; at the same time the relaxation frequency moves to a higher value [5].

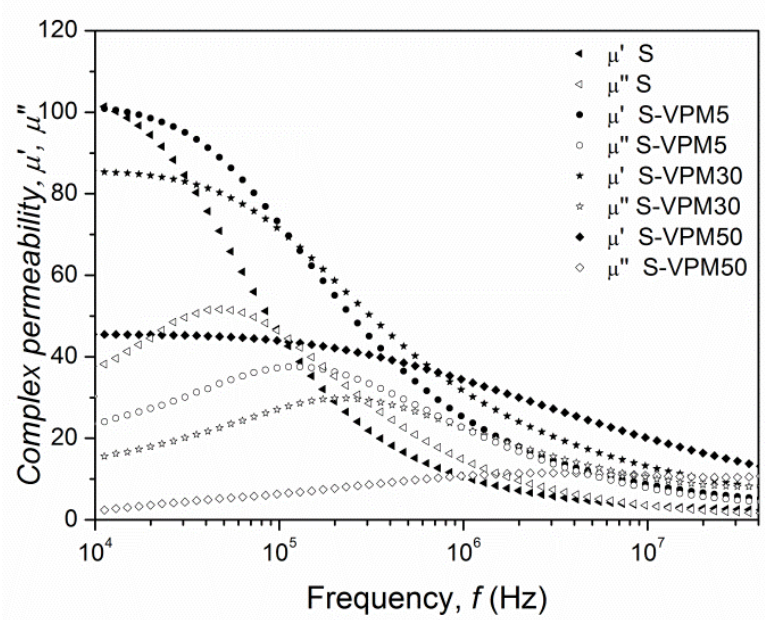

Fig. 7 Comparison of the real $\mu^{\prime}$ and imaginary $\mu^{\prime \prime}$ part of the complex permeability $\mu$ of S-VPM samples, respectively

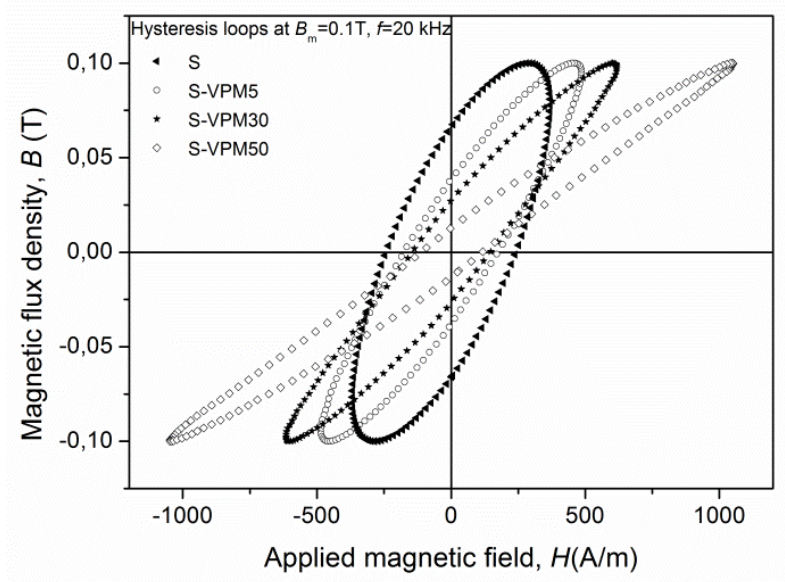

Fig. 8 AC hysteresis loops of bulk S-VPM cores

Table 1 Parameters of the samples

\begin{tabular}{ccccccc}
\hline Sample & $\mathrm{R}$ & $\mathrm{L}$ & S-VPM5 & S-VPM30 & S-VPM50 & S \\
\hline Total losses $[\mathrm{W} / \mathrm{kg}]$ & 254 & 227 & 140 & 170 & 105 & 205 \\
$\begin{array}{c}\left(\mathrm{f}=20 \mathrm{kHz}, \mathrm{B}_{\mathrm{m}}=0.1 \mathrm{~T}\right) \\
\text { Specific resistivity }[\mu \Omega \cdot \mathrm{m}]\end{array}$ & 2.5 & 2.7 & 32 & 105 & 135 & 4.5 \\
Relaxation frequency $[\mathrm{kHz}]$ & 0.2 & 2.7 & 150 & 240 & 3000 & 50 \\
Density $\left[\mathrm{kg} / \mathrm{m}^{3}\right]$ & 6709 & 6730 & 7080 & 6770 & 6100 & 6570
\end{tabular}

The influence of VPM content on the hysteresis loops is given in Fig. 8. The relief of the porosity, density and electrical resistivity influences also the hysteresis loops.
The $\mathrm{Fe}_{73} \mathrm{Cu}_{1} \mathrm{Nb}_{3} \mathrm{Si}_{16} \mathrm{~B}_{7}$ powder has positive influence on the AC core losses of the S-VPM compacted samples.Result of optical microscopy observation of bulk 
sample is documented in Fig. 9. The electrical resistivity of the samples depends not only on the density of the samples but also on the quality of the electrical contacts formed during compaction [6].

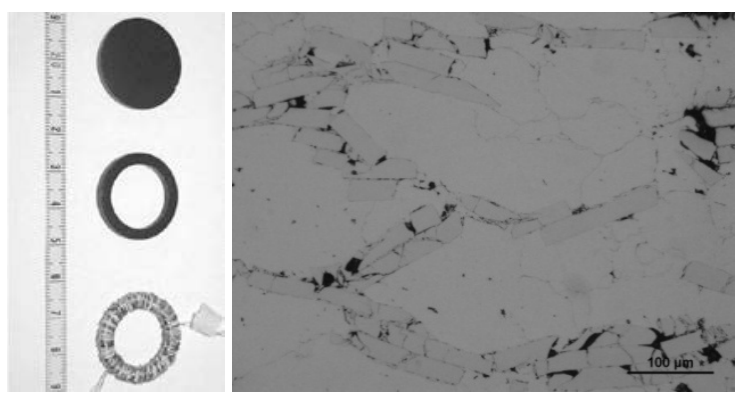

Fig. 9 Compacted S-VPM30 powders cores and crosssectional view of a bulk sample

\section{CONCLUSIONS}

We successfully prepared bulk metallic Fe-based samples consisting of $\mathrm{Fe}_{73} \mathrm{Cu}_{1} \mathrm{Nb}_{3} \mathrm{Si}_{16} \mathrm{~B}_{7}$ and mixed iron insulated powders Somaloy with $\mathrm{Fe}_{73} \mathrm{Cu}_{1} \mathrm{Nb}_{3} \mathrm{Si}_{16} \mathrm{~B}_{7}$, respectively. We have prepared bulk samples in the form of the small cylinders with good soft magnetic properties. From the above study, we conclude that the magnetic properties of the Fe-based samples show dependence to its initial, master powder and annealing conditions. The relatively higher coercivity may be mainly due to the defects and internal stresses created by milling and consolidation. However, it could be decreased greatly after producing higher density bulk materials with lower porosity. The success of forming the ferromagnetic powder compacted material and soft magnetic composite is promising for future development as new type of magnetic materials.

\section{ACKNOWLEDGMENTS}

This work was realized within the frame of the project "The progressive technology for preparation of microcomposite materials for electrotechnology", ITMS 26220220105, which is supported by the Operational Program "Research and Development" financed through European Regional Development Fund. This work was also supported by the Slovak Research and Development Agency under the contract No. APVV-0222-10 MAGCOMP and by the Scientific Grant Agency of the Ministry of Education of Slovak Republic and the Slovak Academy of Sciences, project No. VEGA 1/0861/12 and No. 1/0862/12. Special thanks to Mr. Milan Vitovský of
Vacuumschmelze GmbH \& Co. KG Hanau, Germany for providing of Vitroperm 800 samples.

\section{REFERENCES}

[1] HERZER, G.: Nanocrystalline soft magnetic materials, J. Magn. Magn. Mater., 158, pp. 133-136, 1996.

[2] RAJA, M. M. - PONPANDIAN, N. MAJUMDAR, B. - NARAYANASAMY, M. CHATTOPADHYAY, K.: Soft Magnetic Properties of Nanostructured Finemet Alloy Powder Cores, Mater. Sci. Eng., 304, pp. 1062-1065, 2001.

[3] SHOKROLLAHI, H. - JANGHORBAN, K.: Soft magnetic composite materials (SMCs), Journal of Materials Processing Technology, vol. 189, pp. 1 12, 2007.

[4] FÜZER, J. - KOLLÁR, P. - FÜZEROVÁ, J. ROTH, S.: Soft magnetic properties of nanostructured vitroperm alloy powder cores, IEEE Transactions on Magnetics, vol. 46, 2, pp. 471-474, 2010.

[5] FÜZEROVÁ, J. - FÜZER, J. - KOLLÁR, P. HEGEDÜS, L. - BUREŠ, R. - FÁBEROVÁ, M.: Analysis of the Complex Permeability Versus Frequency of Soft Magnetic Composites Consisting of Iron and $\mathrm{Fe}_{73} \mathrm{Cu}_{1} \mathrm{Nb}_{3} \mathrm{Si}_{16} \mathrm{~B}_{7}$, IEEE Transactions on Magnetisc, vol. 48, 4, pp. 1545-1548, 2012.

[6] KOLLÁR, P. - HEGEDÜS, L. - FÜZER, J. BUREŠ, R. - FÁBEROVÁ, M.: AC Magnetic Properties of Vitroperm Based Composite Materials, Acta Physica Polonica A, vol. 118, pp. 787-789, 2010.

Received November 30, 2012 , accepted February 9, 2013

\section{BIOGRAPHY}

Ján Füzer was born on 22.01.1971. In 1994 he graduated (MSc) with distinction at the department of Solid state physics of the Faculty of Science at P.J.Šafárik University in Košice. He defended his $\mathrm{PhD}$ in the field of magnetic properties of the amorphous and nanocrystalline materials in the bulk, powder and ribbon forms; his thesis title was "The study of the magnetic properties of the soft magnetic properties “. Since 1997 he is working as a scientist with Institute of Physics at the same University. His scientific research is focusing on magnetic properties and complex permeability of bulk soft magnetic materials. 